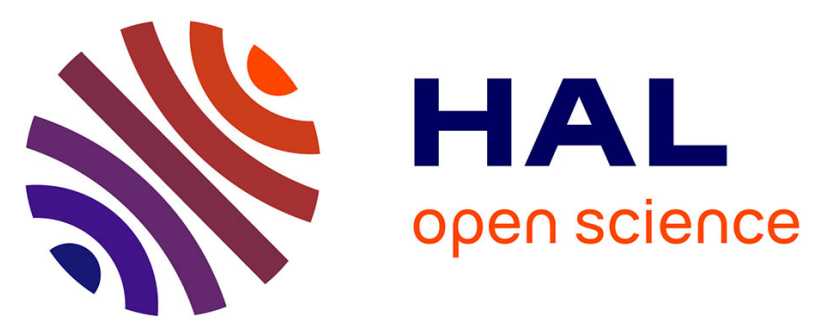

\title{
Does iron overload in metabolic syndrome affect macrophage profile? A case control study
}

Clément Lahaye, Cécile Gladine, Bruno Pereira, Juliette Berger, Giulia Chinetti-Gbaguidi, Fabrice Lainé, Andre Mazur, Marc Ruivard

\section{To cite this version:}

Clément Lahaye, Cécile Gladine, Bruno Pereira, Juliette Berger, Giulia Chinetti-Gbaguidi, et al.. Does iron overload in metabolic syndrome affect macrophage profile? A case control study. Journal of Trace Elements in Medicine and Biology, 2021, 67, pp.126786. 10.1016/j.jtemb.2021.126786 . hal-03246647

\section{HAL Id: hal-03246647 https://hal.science/hal-03246647}

Submitted on 15 Jun 2021

HAL is a multi-disciplinary open access archive for the deposit and dissemination of scientific research documents, whether they are published or not. The documents may come from teaching and research institutions in France or abroad, or from public or private research centers.
L'archive ouverte pluridisciplinaire HAL, est destinée au dépôt et à la diffusion de documents scientifiques de niveau recherche, publiés ou non, émanant des établissements d'enseignement et de recherche français ou étrangers, des laboratoires publics ou privés. 
Does iron overload in metabolic syndrome affect macrophage profile? A case control study

\section{Short title: Macrophage profile in DIOS}

\section{Authors}

\section{Clément Lahaye*}

Université Clermont Auvergne, CHU Clermont-Ferrand, Service de Médecine interne Hôpital Estaing ; INRAE, UNH, Unité de Nutrition Humaine, CRNH Auvergne, F-63000 Clermont-Ferrand, France. clahaye@ chu-clermontferrand.fr

\section{Cécile Gladine*}

Université Clermont Auvergne, INRAE, UNH, Unité de Nutrition Humaine, CRNH Auvergne, F-63000 Clermont-Ferrand, France. cecile.gladine@inra.fr

\section{Bruno Pereira}

Université Clermont Auvergne, CHU Clermont-Ferrand, Unité de biostatistiques, F-63000

Clermont-Ferrand, France. bpereira@chu-clermontferrand.fr

\section{Juliette Berger}

Université Clermont Auvergne, CHU Clermont-Ferrand, Laboratoire d'Hématologie, Hôpital Estaing, F-63000 Clermont-Ferrand, France.jberger@ chu-clermontferrand.fr

\section{Giulia Chinetti-Gbaguidi}

Université Côte d'Azur, CHU, Inserm, C3M, 06000 Nice, France. chinetti.g@ chu-nice.fr Fabrice Lainé 
INSERM CIC 1414, and Liver Unit, CHU Rennes, 35000 Rennes, France.

Fabrice.Laine@chu-rennes.fr

\section{Andrzej Mazur}

Université Clermont Auvergne, INRAE, UNH, Unité de Nutrition Humaine, CRNH Auvergne, F-63000 Clermont-Ferrand, France. andre.mazur@inra.fr

\section{Marc Ruivard}

Université Clermont Auvergne, CHU Clermont-Ferrand, Service de Médecine interne

Hôpital Estaing, F-63000 Clermont-Ferrand, France. mruivard@chu-clermontferrand.fr

* Co first authors

\section{Corresponding author:}

Dr Clément Lahaye

CHU Clermont-Ferrand, Hôpital Estaing, Department of Internal Medicine

1 Rue Lucie Aubrac, 63100 Clermont-Ferrand, France

Tel : + 33473750085

Fax : + 33473754183

clahaye@chu-clermontferrand.fr

Electronic word count: 3,912

Number of figures and tables: 7 


\section{ABSTRACT:}

Aims - Dysmetabolic iron overload syndrome (DIOS) is common but the clinical relevance of iron overload is not understood. Macrophages are central cells in iron homeostasis and inflammation. We hypothesized that iron overload in DIOS could affect the phenotype of monocytes and impair macrophage gene expression.

Methods - This study compared 20 subjects with DIOS to 20 subjects with metabolic syndrome (MetS) without iron overload, and 20 healthy controls. Monocytes were phenotyped by Fluorescence-Activated Cell Sorting (FACS) and differentiated into anti-inflammatory M2 macrophages in the presence of IL-4. The expression of 38 genes related to inflammation, iron metabolism and M2 phenotype was assessed by real-time PCR. Results - FACS showed no difference between monocytes across the three groups. The macrophagic response to IL-4-driven differentiation was altered in four of the five genes of M2 phenotype (MRC1, F13A1, ABCA1, TGM2 but not FABP4), in DIOS vs Mets and controls demonstrating an impaired M2 polarization. The expression profile of inflammatory genes was not different in DIOS vs MetS. Several genes of iron metabolism presented a higher expression in DIOS vs MetS: SCL11A2 (a free iron transporter, $+76 \%, \mathrm{p}=0.04$ ), SOD1 (an antioxidant enzyme, $+27 \%, \mathrm{p}=0.02$ ), and TFRC (the receptor 1 of transferrin, $+59 \%, \mathrm{p}=0.003)$.

Conclusions - In DIOS, macrophage polarization toward the M2 alternative phenotype is impaired but not associated with a pro-inflammatory profile. The up regulation of transferrin receptor 1 (TFRC) in DIOS macrophages suggests an adaptive role that may limit iron toxicity in DIOS. 
Abstract world count: 249

\section{Abbreviations:}

BMI: Body mass index

DIOS: dysmetabolic iron overload syndrome

DMT: divalent metal transporter

FPN: ferroportin

GAPDH: glyceraldehyde 3-phosphate dehydrogenase

HOMA-IR: homeostatic model assessment of insulin resistance

LDH: lactate dehydrogenase

MetS: metabolic syndrome

MR: mannose receptor

MRI: magnetic resonance imaging

NAFLD: non-alcoholic fatty liver disease

NASH: non-alcoholic steatohepatitis

PBMC: peripheral blood mononuclear cells

PPARG: peroxisome proliferator-activated receptor gamma

ROS: reactive oxygen species

usCRP: ultra-sensitive C-reactive protein

RM: resting macrophages

TLDA: TaqMan low-density array 


\section{Keywords}

Dysmetabolic iron overload syndrome; metabolic syndrome; macrophage polarization; inflammation; ferritin

\section{INTRODUCTION}

Insulin resistance-associated hepatic iron overload, referred as dysmetabolic iron overload syndrome (DIOS) [1,2] affects up to $20 \%$ of patients with metabolic syndrome (MetS) and iron could participate to the risk of cardiovascular diseases of patients with MetS. MetS promotes atherosclerosis [3] and NASH [4] through low-grade inflammation; but it is not clear that iron overload in DIOS may enhance this inflammation. In MetS, the infiltration of macrophages in expanding adipose tissue and liver tissue is linked to low-grade inflammation and insulin resistance $[5,6]$.

Monocytes, macrophages and hepatocytes are involved in iron recycling and tissue redistribution [7]. The mesenchymal localisation of iron overload in DIOS suggests the potential involvement of monocytes-macrophages in its pathophysiology.

Monocytes and macrophages produce various inflammatory mediators and growth factors in response to the microenvironment. Macrophages exhibit a broad spectrum of polarization from the classical M1 phenotype, characterized by inflammatory, bactericidal, and proatherogenic properties, to the alternative macrophages M2, which specialise in immunomodulation and tissue repair [8]. M1 and M2 macrophages have been observed in 
various tissues including adipose tissue [9], liver tissue [10] or atherosclerotic plaques $[11,12]$. The ability of macrophages to switch from the M1 to M2 phenotype may drive the resolution of inflammation and limit chronic inflammation [13].

Alternatively activated macrophages have an increased capacity for heme uptake, non-heme iron release into tissues via ferroportin, and the production of anti-inflammatory mediators via heme oxygenase-dependent heme catabolism [14,15]. Macrophage iron overload triggers inflammation via the production of reactive oxygen species (ROS) and influences macrophage polarization. In humans, ex vivo monocyte-differentiated macrophages, raised intracellular iron [16] or iron loading [17] lead to an inflammatory phenotype.

We hypothesized that iron overload in DIOS could affect the phenotype of monocytes and macrophages, and impair macrophage polarization towards the M2 phenotype, which could participate to the potential clinical toxicity of iron in DIOS. The aim of this study was to compare the gene expression profile of M2 polarized macrophages in DIOS patients with those of patients with MetS without iron overload, and healthy volunteers.

\section{METHODS}

\section{Subjects}

The prospective study included three groups of 20 subjects. DIOS participants had hyperferritinemia (450 - $1500 \mathrm{ng} / \mathrm{mL}$ ); hepatic iron content $>50 \mu \mathrm{mol} / \mathrm{g}$ as measured by MRI 
[18]; and at least one criterion of Mets [19]. Mets subjects fulfilled the definition of Mets [23] and had normal serum ferritin levels. The control group (healthy volunteers) had normal serum ferritin and routine laboratory parameter levels and a BMI $<25 \mathrm{~kg} / \mathrm{m}^{2}$. The exclusion criteria were: under 18 year-olds, pregnancy, alcohol (World Health Organization standards) or tobacco consumption, use of anti-diabetic medication, prior therapeutic phlebotomy, type 1 hereditary hemochromatosis, hemolysis (elevated LDH and reticulocytes and low haptoglobin), elevated blood concentrations of liver enzymes (transaminases $>2$ times the normal values), or acute inflammatory syndrome [C-reactive protein (CRP) >15 mg/L]. Subjects were matched by age ( \pm 5 years), gender, BMI $\left( \pm 5 \mathrm{~kg} / \mathrm{m}^{2}\right)$ and waist circumference $( \pm 5 \mathrm{~cm})$ for DIOS and Mets groups.

The control and MetS subjects were recruited from a cohort of volunteers in biomedical research managed by the Clermont-Ferrand Clinical Investigation Centre (CIC). Informed consent was obtained from all individual participants included in the study. The study protocol conforms to the ethical guidelines of the 1975 Declaration of Helsinki as revised in 1983 and received approval from the institution's human research committee (Comité de Protection des Personnes Sud-Est VI, NAU 1100). The study was sponsored by the CHU of Clermont-Ferrand and registered in a public trial registry (NCT 02066012).

All subjects were seen once by a medical doctor and underwent fasting peripheral blood sampling $(50 \mathrm{~mL})$. Blood samples were used to perform routine laboratory analyses, monocyte chemotactic protein (MCP)-1, tumour necrosis factor (TNF), IL-6 and hepcidin plasma determination by enzyme-linked immunosorbent assay (ELISA), phenotyping of monocytes by fluorescence activated cell sorting (FACS), and isolation and differentiation of 
monocytes into RM or M2 macrophages.

\section{Phenotypic characterization of peripheral blood mononuclear cells (PBMC)}

Phenotyping of PBMC was performed using a BD FACS Canto II cytometer equipped with Diva 7.0 software (BD Biosciences, Le Pont de Claix, France) for a multiparametric study. Labelling was carried out on whole blood, as previously described [20]. Two samples were analysed for each subject. The first sample served as a negative control, to compensate for CD14 and CD45 autofluorescence. The second sample contained cell and CD14 APC-H7 (APC-cyanine 7), V450 CD16, MR PE-CyTM 5 (Phycoerythrin cyanine 5), and CD163-PE (Phycoerythrin) antibodies. Lymphocytes were used as a negative control for mannose receptor (MR, coded by MRC1) and CD163 staining. To limit the overlap of emission spectra of fluorochromes, a compensation matrix was automatically calculated using capture beads with Compbeads type antibody (BD Biosciences).

Analysis of monocyte subpopulations was performed by successive windowing: by size (forward scatter) and granularity (side scatter), then in terms of CD45 (pan leukocyte marker) and graininess, and in terms of CD14 and CD16. Monocytes were selected based on their light scatters as well as CD14 and CD16 expression, and divided into sub-populations. Populations P6 (CD14++CD16-) and P3 (CD14++CD16low) were previously reported [21,22] as classical monocytes, P4 (CD14+ CD16+) as intermediate monocytes, and P5 (CD14-CD16++) as non-classical monocytes. Expression of CD163 and MR, two cell surface markers of monocyte/macrophage lineage, was then analysed for each of these subpopulations. CD163 is a scavenger receptor for the hemoglobin-haptoglobin complex, and MR is involved in both the innate and adaptive immune systems as well as in the 
clearance of circulating glycoproteins [23].

\section{Macrophage culture in vitro}

Monocytes were isolated from whole ethylenediamine tetraacetic acid (EDTA) blood using Ficoll gradient centrifugation (GE Healthcare, Velizy-Villacoublay, France) within 2 hours of collection. Monocytes were then placed in Corning ${ }^{\circledR}$ Primaria $^{\mathrm{TM}} 24$-well plastic culture dishes (BD Falcon ${ }^{\mathrm{TM}}$, Dominique Dutscher, Brumath, France) and incubated $\left(37^{\circ} \mathrm{C}\right.$, 5\% $\mathrm{CO}_{2}$ ) in serum-free Roswell Park Memorial Institute (RPMI) 1640 medium (Life Technologies, Illkirch, France). Differentiation of monocytes into resting (RM) or M2 macrophages was performed as previously described [24]. IL-4, a commonly used potent inducer of the macrophage alternative phenotype [25], was used to induce M2 polarization. After 7 days of culture, monocyte-derived macrophages (RM or M2) were recovered in Trizol (Life Technologies) for RNA extraction.

\section{Macrophage RNA extraction and reverse transcription}

Total RNAs were extracted from RM and M2 macrophages by Trizol (Life Technologies) in line with the manufacturer's instructions. Concentration of RNA was measured using the ND-100 Nanodrop (ThermoScientic, Wilmington, USA), and sample integrity was verified using the 2100 Bioanalyzer (Agilent Technologies, Santa Clara, USA). Samples with an RNA integrity number (RIN) greater than 6.5 were used for further analysis. After treatment with DNase (RNase-free DNase I Kit, Fermentas, Fisher Scientific, France), a reverse transcription of RNA into complementary DNA (cDNA) was performed using a High Capacity cDNA Reverse Transcription kit (Life Technologies) in line with the 
manufacturer's instructions. The obtained cDNA were stored until use at $-20^{\circ} \mathrm{C}$.

\section{Gene expression in macrophages}

Pre-amplified cDNA samples were amplified using the Made-to-Order Low Density Array System, TLDA (TaqMan Low Density Array, ThermoFisher Scientific, Paisley, Scotland) in line with the manufacturer's instructions. The analyses were performed on the Applied Biosystems 7900HT system. TLDA was designed to screen for changes in the expression of 48 marker genes relating to monocytes, M2 macrophage polarization (MRC1, F13A1, FABP4, ABCA1, and TGM2), cytokines, chemokines, iron metabolism, transcription factors, lipid metabolism, oxidative stress markers and housekeeping genes (Table 1). Each sample was run in duplicate, and the results analysed using RQ Manager software (Applied Biosystems). Due to insufficient expression or excessive variability among cell donors, CCL18, CX3CR1, CXCL10, CXCL9, INFG, IL6, PPIB, SLC46A1, TNF, and CYBB were excluded from the analysis.

The relative expression of each gene was normalized to the expression level of the housekeeping gene GAPDH (glyceraldehyde-3-phosphate dehydrogenase) and was calculated using the $\triangle \Delta \mathrm{Ct}$ method. The amount of target gene relative to GAPDH was expressed as $2^{-(\Delta \Delta \mathrm{Ct})}$. For the responsiveness of macrophages to IL-4 polarization, results were expressed as a percentage of gene expression $\left(2^{-(\Delta \Delta \mathrm{Ct})}\right)$, relative to the RM macrophages in each group. For the analysis of the basal gene expression profile in RM and M2 macrophages that were assessed individually, results were expressed in MetS and DIOS groups as a percentage of gene expression $\left(2^{-(\Delta \Delta \mathrm{Ct})}\right)$ relative to the control group. 


\section{Cytokine and hepcidin measurement in plasma}

Plasma MCP-1, IL-6, and TNF concentrations were quantified using ELISA kits, in line with the manufacturer's instructions (4ABio, Beijing, China). In the absence of harmonization in the hepcidin-25 assays [26], a hepcidin assay (S-1337 Hepcidin-25 (human)-EIA Kit, Bachem, Budendorf, Germany) was carried out by the French reference laboratory for iron metabolism (INSERM UMR 991, Rennes, France).

\section{Statistical analysis}

The number of subjects required was based on the detection of a difference in two M2 phenotypic markers (MRC1, F13A1) between the three groups (control, MetS, DIOS) after induction with IL4. Considering first-species risk inflation $\alpha$ of 0.017 (to compensate for multiple group comparisons) and a power of at least $80 \%$, the expected minimal difference $\mathrm{D}$ (bilateral) for the macrophage phenotypic marker MRC1 is 16.5 [standard deviation (SD) = 15.55 [24] and F13A1, D $=0.014, \mathrm{SD}=0.013$ ]. In view of the results published by Bories et al., on $\mathrm{N}=13$ per group, these differences appear to be relevant [24]. In our exploratory study, the number of subjects required was calculated according to our ability to recruit and on the calculation of statistical power (assuming a normal distribution of parameters): each group included 20 patients.

Statistical analyses were performed using Stata software (version 13, StataCorp, College Station, USA) and SIMCA (version 13.0, Umetrics, San Jose, USA). Continuous data was expressed as mean \pm SD or median (interquartile range) according to statistical distribution (assumption of Gaussian distribution studied by the Shapiro-Wilk test), and 
compared by analysis of variance (ANOVA), or using the nonparametric Kruskal-Wallis (KW) test when assumptions of ANOVA were not met [(i) normality and (ii) homoscedasticity using the Bartlett test]. When appropriate (omnibus p-value $<0.05$ ), these analyses were followed by a post-hoc test for multiple comparisons: Tukey-Kramer following ANOVA, and Dunn following KW. Multivariate analysis taking into account the simultaneous study of IL-4 fixed effects (yes/no), group (control, MetS, DIOS), and their interaction, were performed using random-effects models to model between and within topic variability. When necessary, a logarithmic transformation was used to achieve normality of dependent variables, and the Wilcoxon test was applied for paired comparisons. All statistical tests were two-sided, and $\mathrm{p}<0.05$ was considered significant. We chose to report all the individual p-values without systematically carrying out mathematical correction for distinct tests [27]. Particular focus was given to the magnitude of improvement and to biological relevance. 


\section{RESULTS}

\section{Demographic and biological characteristics of studied subjects}

Figure 1 shows the selection process for DIOS patients. The mean age was $58 \pm 9$ yrs. (Table 2), and $85 \%$ were men. Compared to the Control group, MetS and DIOS patients had a significantly higher plasma concentration of usCRP, triglycerides, alanine aminotransferase (ALAT), and lower HDL cholesterol. Insulin resistance, calculated by HOMA-IR, was higher

\section{Plasma hepcidin and cytokine concentrations}

Plasma hepcidin concentration was higher in DIOS than in Mets and control groups (Table 3). Hepcidin concentrations were correlated with ferritin $(r=0.79, \mathrm{p}=0.001)$, BMI ( $\mathrm{r}$ $=0.27, \mathrm{p}=0.04)$ and CRP $(\mathrm{r}=0.27, \mathrm{p}=0.04)$. Plasma pro-inflammatory cytokines and chemokines (MCP-1, IL-6, and TNF) were not different between groups.

\section{Monocyte subtype distribution and surface markers}

The distribution of all monocyte subtypes was not different across the three groups (Supplementary Figure 1 and Supplementary Table 1).

\section{Macrophage gene expression}

Macrophages exposed to IL-4 showed significantly higher expression of two markers of M2 polarization compared to resting macrophages in the Control group (median value MRC1, +48\%) and F13A1, +11\%) (Figure 2 and Supplementary Table 2) and in the MetS 
group (MRC1, $+49 \%$ and F13A1, $+114 \%$ ). However, the induction of these M2 markers by IL-4 was not significant in the DIOS group. Other gene expression including FABP4, ABCA1, and TGM2 was modulated by IL-4, especially in the control group, where FABP4 expression increased significantly by $37 \%$, ABCA 1 decreased by $31 \%$, and TGM2 increased by $84 \%$. Most of these effects were not observed in the MetS and DIOS groups except for IL-4 induced FABP4 in the DIOS group $(+74 \%)$. Using a mixed-effects regression model to compare IL4-induced polarization between patient groups, only F13A1 showed a difference between Control and DIOS groups. No intergroup difference was demonstrated among the 35 other genes of interest. (Supplementary Table 2).

To assess whether donor pathophysiological status affects basal macrophage gene expression, RM and M2 macrophages from the MetS and DIOS groups were compared to the Control group. The expression of several genes was significantly affected in RM in MetS and DIOS subjects (Figure 3a-g and Supplementary Table 3.). Gene expression of $A B C A 1$, a cholesterol transporter, or PPARA (Peroxisome Proliferator-Activated receptor alpha), a transcription factor regulating fatty acid and lipoprotein metabolism, gluconeogenesis and ketogenesis, was significantly lower in the MetS group compared to the Control group (-38\% and $-45 \%$ respectively, Figure $3 a-b)$. In the DIOS group, the mRNA abundance of several genes (Figure 3b-e) was different than that of control subjects: CD163, a scavenger receptor involved in the clearance and endocytosis of hemoglobin/haptoglobin with anti-inflammatory properties $(+23 \%, \mathrm{p}=0.06$, Figure $3 \mathrm{C}), S C L 11 A 2$, coding for DMT-1 (divalent metal transporter 1) $(+140 \%, \mathrm{p}=0.04$, Figure 3D). Conversely, the expression of PPARA (-37\%, Figure 3B) and CD14, a co-receptor involved in innate immune response $(-52 \%$, Figure $3 \mathrm{E})$, was significantly lower in the DIOS group compared to the Control 
group.

When the DIOS group was compared to the MetS group, several genes were significantly up-regulated: SCL11A2 (+76\%), SOD1 (Superoxide Dismutase 1), an important antioxidant enzyme (+27\%), and TFRC coding for TfR1 (Transferrin receptor 1), which is involved in iron cellular uptake $(+59 \%)$ (Figure $3 \mathrm{f}-\mathrm{g})$.

Two genes were also differently expressed between the M2 macrophages across the three groups (Figure 4 and supplementary Table 4). M2 macrophages from the MetS group exhibited significantly higher mRNA abundance $(+30 \%)$ of PPAR $\gamma$, a nuclear receptor involved in macrophage inflammatory and immune responses as compared to the Control group. In the DIOS group, the mRNA level of PPAR $\gamma(+46 \%)$ and TFRC $(+45 \%)$ was significantly higher than in the Control group. There was no difference in the expression of these genes between the MetS and DIOS groups.

\section{DISCUSSION AND CONCLUSION}

In the DIOS group, impaired induction of MRC1 and F13A1 in response to IL-4 suggests an alteration of M2 macrophages polarization. This has never been reported before in DIOS but a similar observation was made in severely obese compared to lean subjects [24]. We hypothesize that the pro-inflammatory microenvironment of DIOS monocytes, as illustrated by the high usCRP plasma concentration, affects their polarization capacity. In an recently published MS-based lipidomic profiling on the plasma samples of our volunteers, we were able to show that oxylipin profiling supports a mild but similar oxidative stress and inflammation in both MetS and DIOS subjects compared to control group [28]. The inability of macrophages to differentiate toward M2 polarization could lead to unresolved 
inflammation [13] and may contribute to the pathogenesis of NAFLD [29] and atherosclerosis [30]. However, the impairment of M2 macrophage polarization in the DIOS group was not associated with a pro-inflammatory profile or differences in monocyte subsets. This may be due to the increased PPARG gene expression in DIOS patients that represses the inflammatory response of macrophages [31]. A proteomic study of Adipose Tissue Macrophage from obese patients, has shown a metabolically activated macrophage phenotype, distinct from M1 and M2[32]. This dysmetabolic profile, characterized by overexpression of ABCA1, was experimentally induced by certain fatty acids such as palmitate and was dependent on the transcription factor PPARgamma. Consequently, DIOS macrophages have impaired M2 polarization but weak inflammatory response, possibly because of increased PPARG expression in a pro-inflammatory monocytes microenvironment.

Macrophages capture free iron through transporters DMT1 [33], heme iron via heme carrier protein 1 (HCP-1) and CD163[34], or through iron bound to transferrin (TFR1), they limit iron toxicity via the 2 enzymes heme oxygenase 1 (HO-1) superoxide dismutase 1 (SOD1), and store iron in ferritin and export it via ferroportin (FPN) [35]. Hepcidin, a small peptide produced mainly by the liver and to a lesser extent by adipocytes and macrophages, is over-expressed in cases of iron overload or inflammation (IL-6, LPS) and repressed in the case of anaemia or hypoxia [36]. Hepcidin reduces the amount of circulating iron by inducing proteasome dependent degradation of FPN [37]. Hepcidin reduces iron release by macrophages, leading to iron accumulation in macrophages. As expected, the level of circulating hepcidin was high in our DIOS patients, in relation to elevated intra-hepatic iron 
accumulation. We previously showed that intestinal iron uptake was reduced in DIOS patients [38], but hepcidin reduces intestinal iron absorption by enterocytes [37]. Recently, Rametta et al. suggested a subtle impairment in the ability of hepcidin to restrain iron absorption in DIOS patients [39]. This hepcidin resistance may partly explain the accumulation of iron in DIOS. Nevertheless, our DIOS patients display an overexpression of several genes involved in iron metabolism (SCL11A2, SOD1, TFRC), without an overexpression of ferroportin (coded by SCL40A1), essential for iron export from macrophages. Surprisingly, DIOS patients showed no different expression of ferritin (FTL and FTH1, encoding the light chain and heavy chain, respectively). These elements could participate in the increase of labile intra macrophagic iron which in turn could impact macrophage polarization [16]. Unfortunately, the design of our study did not allow us to measure it directly.

Taken together, these results support the capacity of macrophages to adapt to their microenvironment, which, in the case of DIOS, results in limiting the accumulation of circulating iron and its potential toxicity. Although this was an ex-vivo study conducted in a limited number of volunteers with inherent inter-individual variability, our results provide new insights into the understanding of DIOS and are consistent with recent clinical trials showing no benefit to bloodletting in NAFLD and DIOS subjects. In NAFLD patients, Britton et al. found a significant inverse correlation between hepatic iron content and insulin resistance or hepatic steatosis, and venesection had no effect on the serum concentration of six major adipokines [40]. Moreover, Adams et al. showed that iron depletion failed to improve hepatic steatosis measured by MRI, serum ALT, blood glucose, HOMA-IR and 
insulin sensitivity index in an NAFLD patient with or without initial hyperferritinemia [41]. In a large randomized control study involving 274 non diabetic French patients with DIOS, Lainé et al. found no benefit to iron depletion by phlebotomy in liver enzymes, hepatic fat or insulin resistance venesections, compared to lifestyle and diet advice [42]. These results were confirmed in a recent meta-analysis [43].

Our study shows the adaptive capacity of macrophages in DIOS. Gene expression analysis of macrophages from a DIOS population highlights an impairment in polarization toward the M2 alternative macrophages without a pro-inflammatory profile. Moreover, macrophages from DIOS patients play a major regulatory role by overexpressing TFRC, thus potentially limiting the toxicity of iron overload. This adaptation seems in accordance with clinical trials that showed no clinical benefit in the reduction of iron overload in DIOS.

\section{Author contributions:}

Clément Lahaye: Conceptualization; Data curation; Formal analysis; Investigation; Methodology; Project administration; Resources; Supervision; Validation; Visualization; original draft; review \& editing.

Cécile Gladine: Conceptualization; Data curation; Formal analysis; Investigation; Methodology; Project administration; Resources; Supervision; Validation; Visualization; original draft; review \& editing. 
Bruno Pereira : Conceptualization; Data curation; Formal analysis; Methodology; Validation; Visualization; original draft; review \& editing.

Juliette Berger: Conceptualization; Data curation; Formal analysis; Investigation; Methodology; Validation; Visualization; review \& editing.

Giulia Chinetti-Gbaguidi : Conceptualization; Methodology; Validation; review \& editing.

Fabrice Lainé : Conceptualization; Methodology; Validation; review \& editing.

Andrzej Mazur : Conceptualization; Data curation; Formal analysis; Methodology; Project administration; Resources; Supervision; Validation; original draft; review \& editing.

Marc Ruivard : Conceptualization; Data curation; Methodology; Project administration; Resources; Supervision; Validation; Visualization; original draft; review \& editing.

Ethical approval: All the procedures performed in studies involving human participants were carried out in accordance with the ethical standards of the institutional and/or national research committee and with the 1964 Helsinki declaration and its later amendments, or with comparable ethical standards. 


\section{Acknowledgements:}

We want to thank the entire team at the Clermont-Ferrand Clinical Investigation Center, Dominique Bayle and Séverine Thien for their technical assistance, the volunteers who participated in the study, and the UMR 991 INSERM unit for their technical expertise in measuring hepcidin.

\section{Funding:}

This study was funded by the University Hospital of Clermont-Ferrand (grant number Ruivard AOI 2013) and by the French Society of Internal Medicine (grant Marcel Simon 2014). The sponsors did not in any way participate in study design; collection, analysis and interpretation of data; in the writing of the report; and in the decision to submit the article for publication.

\section{Conflict of Interest: none}

\section{REFERENCES}

[1] Mendler MH, Turlin B, Moirand R, Jouanolle AM, Sapey T, Guyader D, et al. Insulin resistance-associated hepatic iron overload. Gastroenterology 1999;117:1155-63.

[2] Moirand R, Mortaji AM, Loréal O, Paillard F, Brissot P, Deugnier Y. A new syndrome of liver iron overload with normal transferrin saturation. Lancet 1997;349:95-7. https://doi.org/10.1016/S0140-6736(96)06034-5. 
[3] Libby P, Ridker PM, Hansson GK. Progress and challenges in translating the biology of atherosclerosis. Nature 2011;473:317-25. https://doi.org/10.1038/nature10146.

[4] Duarte N, Coelho IC, Patarrão RS, Almeida JI, Penha-Gonçalves C, Macedo MP. How Inflammation Impinges on NAFLD: A Role for Kupffer Cells. BioMed Res Int 2015. https://doi.org/10.1155/2015/984578.

[5] Obstfeld AE, Sugaru E, Thearle M, Francisco A-M, Gayet C, Ginsberg HN, et al. C-C chemokine receptor 2 (CCR2) regulates the hepatic recruitment of myeloid cells that promote obesity-induced hepatic steatosis. Diabetes 2010;59:916-25. https://doi.org/10.2337/db09-1403.

[6] Castoldi A, Naffah de Souza C, Câmara NOS, Moraes-Vieira PM. The Macrophage Switch in Obesity Development. Front Immunol 2015;6:637. https://doi.org/10.3389/fimmu.2015.00637.

[7] Gaetano C, Massimo L, Alberto M. Control of iron homeostasis as a key component of macrophage polarization. Haematologica 2010;95:1801-3. https://doi.org/10.3324/haematol.2010.030239.

[8] Chinetti-Gbaguidi G, Staels B. Macrophage polarization in metabolic disorders: functions and regulation. Curr Opin Lipidol 2011;22:365-72. https://doi.org/10.1097/MOL.0b013e32834a77b4.

[9] Sun K, Kusminski CM, Scherer PE. Adipose tissue remodeling and obesity. J Clin Invest 2011;121:2094-101. https://doi.org/10.1172/JCI45887.

[10] Tacke F, Zimmermann HW. Macrophage heterogeneity in liver injury and fibrosis. J Hepatol 2014;60:1090-6. https://doi.org/10.1016/j.jhep.2013.12.025.

[11] Moore KJ, Tabas I. Macrophages in the pathogenesis of atherosclerosis. Cell 2011;145:341-55. https://doi.org/10.1016/j.cell.2011.04.005.

[12] Fenyo IM, Gafencu AV. The involvement of the monocytes/macrophages in chronic inflammation associated with atherosclerosis. Immunobiology 2013;218:1376-84. https://doi.org/10.1016/j.imbio.2013.06.005.

[13] Viola J, Soehnlein O. Atherosclerosis - A matter of unresolved inflammation. Semin Immunol 2015;27:184-93. https://doi.org/10.1016/j.smim.2015.03.013.

[14] Cairo G, Recalcati S, Mantovani A, Locati M. Iron trafficking and metabolism in macrophages: contribution to the polarized phenotype. Trends Immunol 2011;32:241-7. https://doi.org/10.1016/j.it.2011.03.007.

[15] Naito Y, Takagi T, Higashimura Y. Heme oxygenase-1 and anti-inflammatory M2 macrophages. Arch Biochem Biophys 2014;564:83-8. https://doi.org/10.1016/j.abb.2014.09.005.

[16] Valenti L, Dongiovanni P, Motta BM, Swinkels DW, Bonara P, Rametta R, et al. Serum hepcidin and macrophage iron correlate with MCP-1 release and vascular damage in patients with metabolic syndrome alterations. Arterioscler Thromb Vasc Biol 2011;31:683-90. https://doi.org/10.1161/ATVBAHA.110.214858.

[17] Mehta V, Pei W, Yang G, Li S, Swamy E, Boster A, et al. Iron Is a Sensitive Biomarker for Inflammation in Multiple Sclerosis Lesions. PLoS ONE 2013;8:e57573. https://doi.org/10.1371/journal.pone.0057573.

[18] Gandon Y, Olivié D, Guyader D, Aubé C, Oberti F, Sebille V, et al. Non-invasive assessment of hepatic iron stores by MRI. Lancet 2004;363:357-62. https://doi.org/10.1016/S0140-6736(04)15436-6. 
[19] Alberti KGM, Zimmet P, Shaw J. The metabolic syndrome-a new worldwide definition. The Lancet 2005;366:1059-62.

[20] Abeles RD, McPhail MJ, Sowter D, Antoniades CG, Vergis N, Vijay GKM, et al. CD14, CD16 and HLA-DR reliably identifies human monocytes and their subsets in the context of pathologically reduced HLA-DR expression by CD14(hi) /CD16(neg) monocytes: Expansion of CD14(hi) /CD16(pos) and contraction of CD14(lo) /CD16(pos) monocytes in acute liver failure. Cytom Part J Int Soc Anal Cytol 2012;81:823-34. https://doi.org/10.1002/cyto.a.22104.

[21] Gordon S, Taylor PR. Monocyte and macrophage heterogeneity. Nat Rev Immunol 2005;5:953-64. https://doi.org/10.1038/nri1733.

[22] Devêvre EF, Renovato-Martins M, Clément K, Sautès-Fridman C, Cremer I, Poitou C. Profiling of the three circulating monocyte subpopulations in human obesity. $\mathrm{J}$ Immunol Baltim Md 1950 2015;194:3917-23. https://doi.org/10.4049/jimmunol.1402655.

[23] Azad AK, Rajaram MVS, Schlesinger LS. Exploitation of the Macrophage Mannose Receptor (CD206) in Infectious Disease Diagnostics and Therapeutics. J Cytol Mol Biol 2014;1. https://doi.org/10.13188/2325-4653.1000003.

[24] Bories G, Caiazzo R, Derudas B, Copin C, Raverdy V, Pigeyre M, et al. Impaired alternative macrophage differentiation of peripheral blood mononuclear cells from obese subjects. Diabetes Vasc Dis Res Off J Int Soc Diabetes Vasc Dis 2012;9:189-95. https://doi.org/10.1177/1479164111430242.

[25] Bouhlel MA, Derudas B, Rigamonti E, Dièvart R, Brozek J, Haulon S, et al. PPARgamma activation primes human monocytes into alternative M2 macrophages with anti-inflammatory properties. Cell Metab 2007;6:137-43. https://doi.org/10.1016/j.cmet.2007.06.010.

[26] Kroot JJC, van Herwaarden AE, Tjalsma H, Jansen RTP, Hendriks JCM, Swinkels DW. Second round robin for plasma hepcidin methods: First steps toward harmonization. Am J Hematol 2012;87:977-83. https://doi.org/10.1002/ajh.23289.

[27] Feise RJ. Do multiple outcome measures require p-value adjustment? BMC Med Res Methodol 2002;2:8. https://doi.org/10.1186/1471-2288-2-8.

[28] Dalle C, Lahaye C, Bosviel R, Ruivard M, Gladine C, Mazur A. MS-based Lipidomic Profiling of Oxylipins Supports Mild Inflammation in Dysmetabolic Iron Overload Syndrome Affected Patients (P08-046-19). Curr Dev Nutr 2019;3. https://doi.org/10.1093/cdn/nzz044.P08-046-19.

[29] Alisi A, Carpino G, Oliveira FL, Panera N, Nobili V, Gaudio E. The Role of Tissue Macrophage-Mediated Inflammation on NAFLD Pathogenesis and Its Clinical Implications. Mediators Inflamm 2017. https://doi.org/10.1155/2017/8162421.

[30] Peled M, Fisher EA. Dynamic Aspects of Macrophage Polarization during Atherosclerosis Progression and Regression. Front Immunol 2014;5. https://doi.org/10.3389/fimmu.2014.00579.

[31] Rigamonti E, Chinetti-Gbaguidi G, Staels B. Regulation of macrophage functions by PPAR-alpha, PPAR-gamma, and LXRs in mice and men. Arterioscler Thromb Vasc Biol 2008;28:1050-9. https://doi.org/10.1161/ATVBAHA.107.158998.

[32] Kratz M, Coats BR, Hisert KB, Hagman D, Mutskov V, Peris E, et al. Metabolic dysfunction drives a mechanistically distinct proinflammatory phenotype in adipose 
tissue macrophages. Cell Metab 2014;20:614-25.

https://doi.org/10.1016/j.cmet.2014.08.010.

[33] Mims MP, Prchal JT. Divalent metal transporter 1. Hematol Amst Neth 2005;10:339-45. https://doi.org/10.1080/10245330500093419.

[34] Yang H, Wang H, Levine YA, Gunasekaran MK, Wang Y, Addorisio M, et al. Identification of CD163 as an antiinflammatory receptor for HMGB1-haptoglobin complexes. JCI Insight n.d.;1. https://doi.org/10.1172/jci.insight.85375.

[35] Drakesmith H, Nemeth E, Ganz T. Ironing out Ferroportin. Cell Metab 2015;22:777-87. https://doi.org/10.1016/j.cmet.2015.09.006.

[36] Ganz T. Macrophages and systemic iron homeostasis. J Innate Immun 2012;4:446-53. https://doi.org/10.1159/000336423.

[37] Ward D, Kaplan J. Ferroportin-mediated iron transport: expression and regulation. Biochim Biophys Acta 2012;1823:1426-33. https://doi.org/10.1016/j.bbamcr.2012.03.004.

[38] Ruivard M, Lainé F, Ganz T, Olbina G, Westerman M, Nemeth E, et al. Iron absorption in dysmetabolic iron overload syndrome is decreased and correlates with increased plasma hepcidin. J Hepatol 2009;50:1219-25. https://doi.org/10.1016/j.jhep.2009.01.029.

[39] Rametta R, Dongiovanni P, Pelusi S, Francione P, Iuculano F, Borroni V, et al. Hepcidin resistance in dysmetabolic iron overload. Liver Int Off J Int Assoc Study Liver 2016;36:1540-8. https://doi.org/10.1111/liv.13124.

[40] Britton L, Bridle K, Reiling J, Santrampurwala N, Wockner L, Ching H, et al. Hepatic iron concentration correlates with insulin sensitivity in nonalcoholic fatty liver disease. Hepatol Commun 2018;2:644-53. https://doi.org/10.1002/hep4.1190.

[41] Adams LA, Crawford DH, Stuart K, House MJ, Pierre TGS, Webb M, et al. The impact of phlebotomy in nonalcoholic fatty liver disease: A prospective, randomized, controlled trial. Hepatology 2015;61:1555-64. https://doi.org/10.1002/hep.27662.

[42] Lainé F, Ruivard M, Loustaud-Ratti V, Bonnet F, Calès P, Bardou-Jacquet E, et al. Metabolic and hepatic effects of bloodletting in dysmetabolic iron overload syndrome: A randomized controlled study in 274 patients. Hepatol Baltim Md 2017;65:465-74. https://doi.org/10.1002/hep.28856.

[43] Murali AR, Gupta A, Brown K. Systematic review and meta-analysis to determine the impact of iron depletion in dysmetabolic iron overload syndrome and non-alcoholic fatty liver disease. Hepatol Res Off J Jpn Soc Hepatol 2018;48:E30-41. https://doi.org/10.1111/hepr.12921. 


\section{Figure captions}

Figure 1. Recruitment of the patients into the DIOS, MetS, and Control groups.

DIOS: dysmetabolic iron overload syndrome; MetS: metabolic syndrome

Figure 2. Responsiveness to IL-4 induction of macrophages from Control, MetS and DIOS subjects ( $\mathrm{n}=20$ per group)

Monocytes from control, MetS or DIOS subjects were differentiated in the presence (M2 macrophages) or in the absence (RM - resting macrophages) of IL-4 (15 ng/mL) for 7 days. At the end of differentiation, mRNA was extracted and the expression of selected M2 polarization markers (MRC1, F13A1, FABP4, ABCA1, TGM2) was determined by TaqMan Low Density Arrays (TLDA). The relative expression (\% of mean resting macrophage expression) of each gene was calculated and represented as median $+/$ - interquartile and compared by Wilcoxon tests. A mixed-effects regression model was used to compare IL4-induced polarization between patient groups. Resting macrophages (RM) are shown in light grey and IL4-treated macrophages (M2) are shown in dark grey.

Figure 3. Relative expression of selected genes of interest in resting macrophages from MetS and DIOS patients in comparison with control subjects ( $\mathrm{n}=20$ per group).

Panel $\mathrm{A}=\mathrm{ABCA} 1$, panel $\mathrm{B}=$ PPARA, panel $\mathrm{C}=\mathrm{CD} 163$, panel $\mathrm{D}=\mathrm{SC1} 11 \mathrm{~A} 2$, panel $\mathrm{E}=$ $\mathrm{CD} 14$, panel $\mathrm{F}=\mathrm{SOD} 1$, panel $\mathrm{G}=\mathrm{TFRC}$ 
Monocytes from control, MetS or DIOS subjects were differentiated into resting macrophages (RM) after 7 days of culture in RPMI medium. At the end of differentiation, mRNA was extracted and the expression of selected genes of interest related to cholesterol efflux (ABCA1), lipid metabolism (PPARA), iron uptake (SCL11A2, TFRC), and limitation of oxidative stress (SOD1) were analyzed by TaqMan Low Density Arrays (TLDA). The relative expression (\% of mean control expression) of each gene was calculated and compared by ANOVA or the nonparametric Kruskal-Wallis (KW) tests. Statistical significance is indicated by $*$ for $\mathrm{p}<0.05$ or $* *$ for $<0.01$

Figure 4. Relative expression of selected genes of interest related to iron uptake (TFR1, panel A) and inflammation (PPARG, panel B) in M2 macrophages from MetS or DIOS patients compared with control subjects ( $n=20$ per group).

Monocytes from control, MetS or DIOS subjects were differentiated into M2 macrophages in the presence of IL-4 (15 ng/mL) for 7 days. At the end of differentiation, mRNA was extracted and expression of selected genes of interest related to iron uptake (TFRC) and inflammation (PPARG) were analyzed by TaqMan Low Density Arrays (TLDA). The relative expression (\% of mean control expression) of each gene was calculated and compared by ANOVA or the nonparametric Kruskal-Wallis (KW) tests. Statistical significance is indicated by $*$ for $\mathrm{p}<0.05$ or $* *$ for $<0.01$ 
Patients diagnosed with DIOS ( $\mathrm{n}=301)$

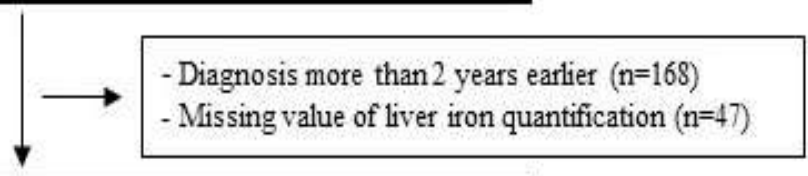

Patients contacted to participate $(n=86)$

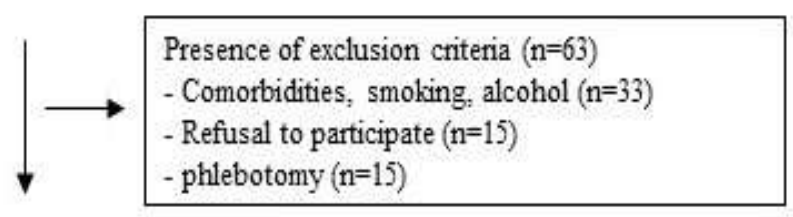

Eligible and volunteers

DIOS patients $(n=23)$

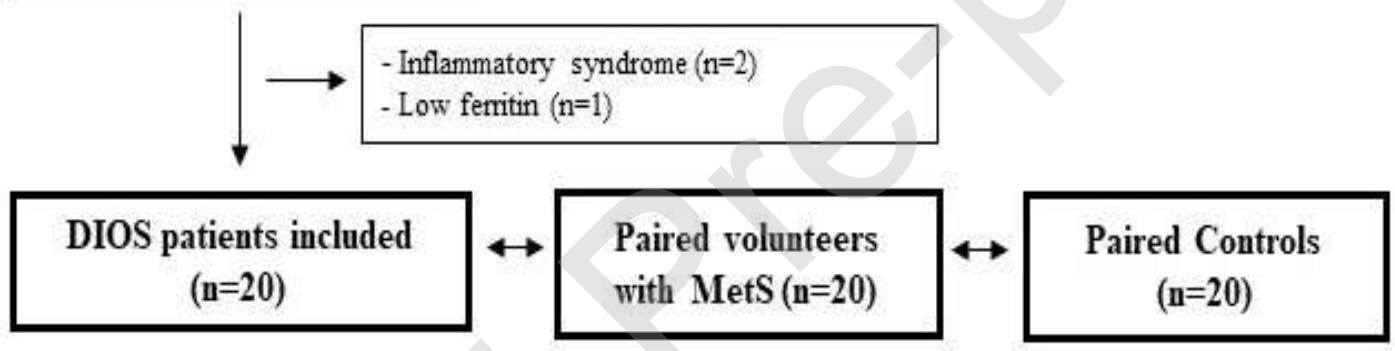



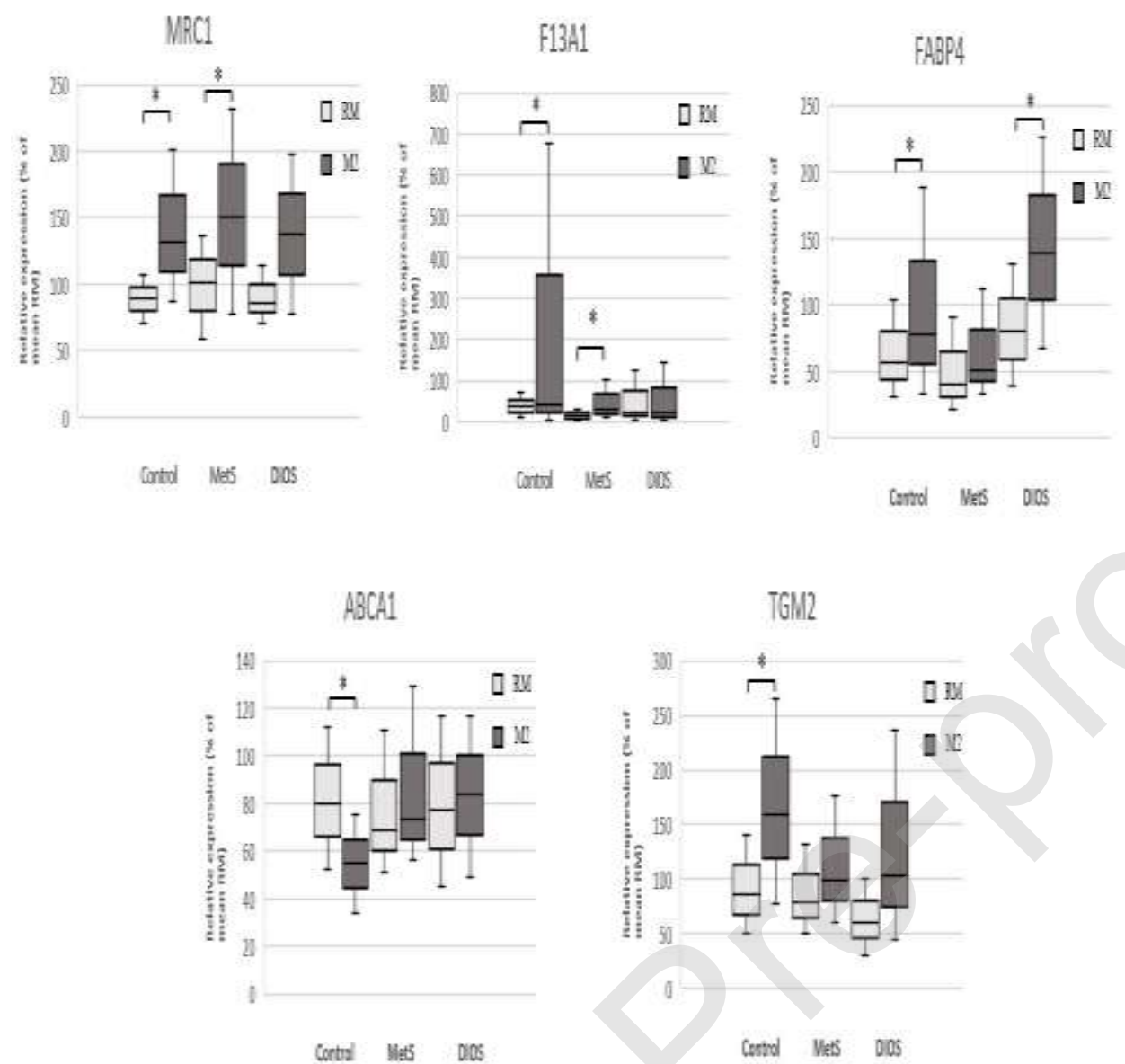


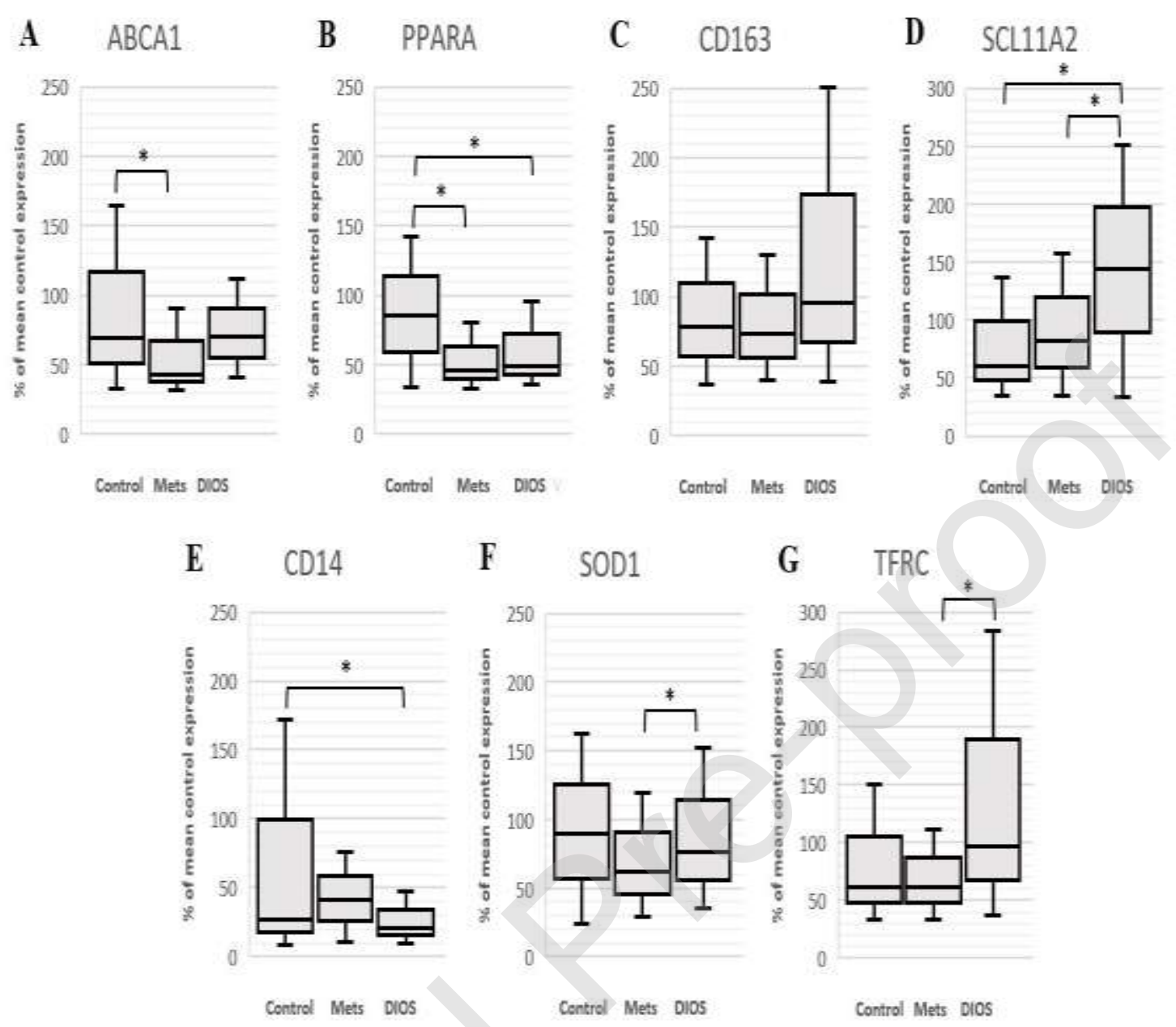



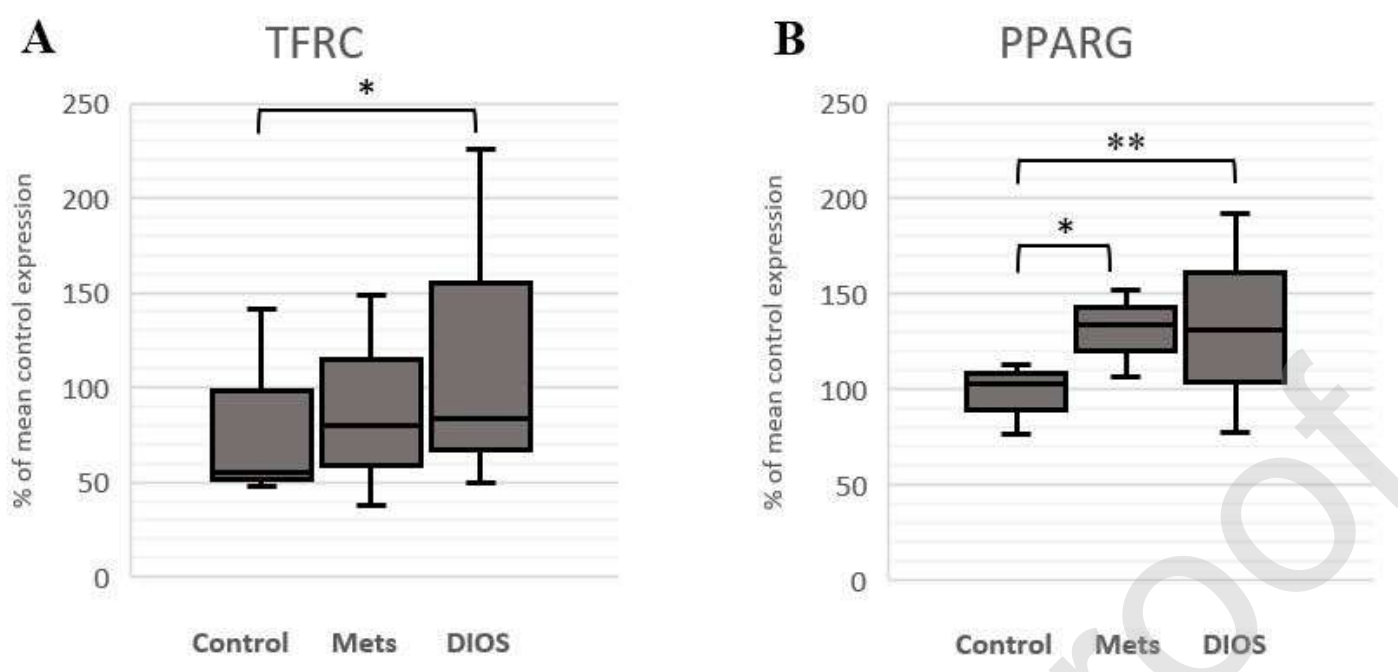
Table 1. List of genes analyzed within the customized Taqman Low Density Array (TLDA) Card

\begin{tabular}{|c|c|c|}
\hline $\begin{array}{c}\text { Gene } \\
\text { symbol }\end{array}$ & Function & Gene name \\
\hline GAPDH & $\begin{array}{l}\text { Housekeeping } \\
\text { gene }\end{array}$ & $\begin{array}{c}\text { glyceraldehyde-3-phosphate } \\
\text { dehydrogenase }\end{array}$ \\
\hline CD14 & $\begin{array}{c}\text { Monocyte } \\
\text { marker }\end{array}$ & CD14-Hs02621496_s1 \\
\hline $\begin{array}{l}\text { FCGR3B; } \\
\text { FCGR3A }\end{array}$ & $\begin{array}{l}\text { Monocyte } \\
\text { marker }\end{array}$ & FCGR3B;FCGR3A-Hs00275547_m1 $\begin{array}{c}\text { Fc fragment of IgG, low affinity IIIb, } \\
\text { receptor (CD16b),Fc fragment of IgG, low } \\
\text { affinity IIIa, receptor (CD16a) }\end{array}$ \\
\hline CCR2 & $\begin{array}{l}\text { Monocyte } \\
\text { marker }\end{array}$ & chemokine ( $\mathrm{C}-\mathrm{C}$ motif) receptor 2 \\
\hline SELL & $\begin{array}{l}\text { Monocyte } \\
\text { marker }\end{array}$ & SELL-Hs00174151_m1 \\
\hline FTH1 & $\begin{array}{c}\text { Iron } \\
\text { metabolism }\end{array}$ & FTH1-Hs01694011_s1 \\
\hline FTL & $\begin{array}{c}\text { Iron } \\
\text { metabolism }\end{array}$ & ferritin, light polypeptide \\
\hline CD163 & $\begin{array}{c}\text { Immune } \\
\text { system }\end{array}$ & CD163-Hs00174705_m1 \\
\hline TGM2 & $\begin{array}{l}\text { Monocyte } \\
\text { marker }\end{array}$ & TGM2-Hs00190278_m1 \\
\hline$P P I B$ & $\begin{array}{l}\text { Immune } \\
\text { system }\end{array}$ & peptidylprolyl isomerase B (cyclophilin B) \\
\hline GTF2B & Transcription & general transcription factor IIB \\
\hline
\end{tabular}




\begin{tabular}{|c|c|c|}
\hline & factor & \\
\hline MRC1 & $\begin{array}{l}\text { Macrophage } \\
\text { polarization } \\
\text { marker }\end{array}$ & mannose receptor, $\mathrm{C}$ type 1 \\
\hline F13A1 & $\begin{array}{l}\text { Macrophage } \\
\text { polarization } \\
\text { marker }\end{array}$ & coagulation factor XIII, A1 polypeptide \\
\hline TFRC & $\begin{array}{c}\text { Iron } \\
\text { metabolism }\end{array}$ & transferrin receptor $1(\mathrm{p} 90, \mathrm{CD} 71)$ \\
\hline LRP1 & $\begin{array}{c}\text { Iron } \\
\text { metabolism }\end{array}$ & $\begin{array}{l}\text { low density lipoprotein receptor-related } \\
\text { protein } 1\end{array}$ \\
\hline SLC11A2 & $\begin{array}{c}\text { Iron } \\
\text { metabolism }\end{array}$ & $\begin{array}{l}\text { solute carrier family } 11 \text { (proton-coupled } \\
\text { divalent metal ion transporter), member } 2\end{array}$ \\
\hline HAMP & $\begin{array}{c}\text { Iron } \\
\text { metabolism }\end{array}$ & hepcidin antimicrobial peptide \\
\hline SLC40A1 & $\begin{array}{c}\text { Iron } \\
\text { metabolism }\end{array}$ & $\begin{array}{l}\text { solute carrier family } 40 \text { (iron-regulated } \\
\text { transporter), member } 1\end{array}$ \\
\hline HMOX1 & $\begin{array}{c}\text { Iron } \\
\text { metabolism }\end{array}$ & HMOX1-Hs01110250_m1 \\
\hline$A T F 1$ & $\begin{array}{l}\text { Transcription } \\
\text { factor }\end{array}$ & activating transcription factor 1 \\
\hline PPARG & $\begin{array}{c}\text { Transcription } \\
\text { factor }\end{array}$ & $\begin{array}{l}\text { peroxisome proliferator-activated receptor } \\
\text { gamma }\end{array}$ \\
\hline PPARA & $\begin{array}{l}\text { Transcription } \\
\text { factor }\end{array}$ & $\begin{array}{l}\text { peroxisome proliferator-activated receptor } \\
\text { alpha }\end{array}$ \\
\hline CLEC7A & $\begin{array}{c}\text { Lipid } \\
\text { metabolism }\end{array}$ & C-type lectin domain family 7 , member A \\
\hline$F A B P 4$ & $\begin{array}{c}\text { Lipid } \\
\text { metabolism }\end{array}$ & fatty acid binding protein 4 , adipocyte \\
\hline
\end{tabular}




\begin{tabular}{|c|c|c|}
\hline$A B C A 1$ & $\begin{array}{c}\text { Lipid } \\
\text { metabolism }\end{array}$ & $\begin{array}{l}\text { ATP-binding cassette, sub-family A } \\
\text { (ABC1), member } 1\end{array}$ \\
\hline NR1H3 & $\begin{array}{l}\text { Transcription } \\
\text { factor }\end{array}$ & $\begin{array}{c}\text { nuclear receptor subfamily } 1 \text {, group } \mathrm{H} \text {, } \\
\text { member } 3\end{array}$ \\
\hline NR1H2 & $\begin{array}{l}\text { Transcription } \\
\text { factor }\end{array}$ & $\begin{array}{l}\text { nuclear receptor subfamily } 1 \text {, group } \mathrm{H} \text {, } \\
\text { member } 2\end{array}$ \\
\hline IL10 & Cytokine & IL10-Hs00961622_m1 \\
\hline SOCS3 & Cytokine & suppressor of cytokine signaling 3 \\
\hline$H L A-D R A$ & $\begin{array}{l}\text { Immune } \\
\text { system }\end{array}$ & $\begin{array}{c}\text { HLA-DRA-Hs00219575_m1 major histocompatibility complex, class II, } \\
\text { DR alpha }\end{array}$ \\
\hline ILIB & Cytokine & interleukin 1 , beta \\
\hline IL6 & Cytokine & interleukin 6 (interferon, beta 2) \\
\hline TGFB1 & Growth factor & transforming growth factor, beta 1 \\
\hline CCL2 & Chemokine & chemokine (C-C motif) ligand 2 \\
\hline CCL3 & Chemokine & chemokine (C-C motif) ligand 3 \\
\hline GPXI & $\begin{array}{l}\text { Oxidative } \\
\text { stress }\end{array}$ & GPX1-Hs00829989_gH \\
\hline SOD1 & $\begin{array}{l}\text { Oxidative } \\
\text { stress }\end{array}$ & superoxide dismutase 1 , soluble \\
\hline PTGS2 & $\begin{array}{l}\text { Oxidative } \\
\text { stress }\end{array}$ & $\begin{array}{c}\text { prostaglandin-endoperoxide synthase } 2 \\
\text { (prostaglandin } \mathrm{G} / \mathrm{H} \text { synthase and } \\
\text { cyclooxygenase) }\end{array}$ \\
\hline SRA1 & $\begin{array}{c}\text { Lipid } \\
\text { metabolism }\end{array}$ & steroid receptor RNA activator 1 \\
\hline
\end{tabular}


Table 2. Clinical characteristics of subjects in the Control, MetS, and DIOS groups ( $\mathrm{n}=20$ per group)

\begin{tabular}{|c|c|c|c|}
\hline & Control & MetS & DIOS \\
\hline Age (y) & $57 \pm 9$ & $57 \pm 9$ & $58 \pm 8$ \\
\hline Female (n \%) & $3(15)$ & $3(15)$ & $3(15)$ \\
\hline Systolic blood pressure (mmHg) & $120 \pm 6$ & $129 \pm 12$ & $131 \pm 11$ \\
\hline Diastolic blood pressure (mmHg) & $80 \pm 3$ & $84 \pm 8$ & $87 \pm 5$ \\
\hline Heart rate $(\mathrm{bpm})$ & $66 \pm 8$ & $67 \pm 7$ & $70 \pm 5$ \\
\hline $\mathrm{BMI}\left(\mathrm{kg} / \mathrm{m}^{2}\right)$ & $23.1 \pm 1.6^{\mathrm{a}}$ & $29.4 \pm 2.9^{b}$ & $28.8 \pm 3.8^{\mathrm{b}}$ \\
\hline Waist size $(\mathrm{cm})$ & $86 \pm 6^{\mathrm{a}}$ & $103 \pm 9^{b}$ & $102 \pm 10^{\mathrm{b}}$ \\
\hline Liver Iron quantification by MRI $(\mu \mathrm{moL} / \mathrm{g})$ & NA & NA & $72.3 \pm 28.9$ \\
\hline
\end{tabular}




\begin{tabular}{|cccc|}
\hline Triglycerides (g/L) & $0.79 \pm 0.24^{\mathrm{a}}$ & $1.39 \pm 0.63^{\mathrm{b}}$ & $1.61 \pm 0.80^{\mathrm{b}}$ \\
\hline HDL cholesterol $(\mathrm{g} / \mathrm{L})$ & $0.68 \pm 0.11^{\mathrm{a}}$ & $0.54 \pm 0.09^{\mathrm{b}}$ & $0.46 \pm 0.09^{\mathrm{c}}$ \\
\hline LDL cholesterol $(\mathrm{g} / \mathrm{L})$ & $1.34 \pm 0.40$ & $1.36 \pm 0.37$ & $1.23 \pm 0.31$ \\
\hline ASAT (IU/L) & $24 \pm 6$ & $25 \pm 6$ & $27 \pm 7$ \\
\hline ALAT (IU/L) & $30 \pm 8^{\mathrm{a}}$ & $40 \pm 17^{\mathrm{b}}$ & $43 \pm 10^{\mathrm{b}}$ \\
\hline Transferrin saturation $(\%)$ & $29.1 \pm 7.9$ & $31.0 \pm 8.4$ & $32.7 \pm 11.4$ \\
\hline Ferritin ( $\mu \mathrm{g} / \mathrm{L})$ & $116 \pm 93^{\mathrm{a}}$ & $194 \pm 13^{\mathrm{b}}$ & $697 \pm 176^{\mathrm{c}}$ \\
\hline usCRP (g/L) & & \\
\hline HOMA-IR index & $0.74 \pm 0.48^{\mathrm{a}}$ & $1.89 \pm 1.02^{\mathrm{b}}$ & $2.47 \pm 3.08^{\mathrm{b}}$ \\
\hline & $1.03 \pm 1.22^{\mathrm{a}}$ & $2.20 \pm 1.66^{\mathrm{b}}$ & $2.60 \pm 1.53^{\mathrm{b}}$ \\
\hline & & & \\
\hline
\end{tabular}

HOMA-IR: homeostatic model assessment of insulin resistance; NA: Not available; Us: ultra-sensitive, bpm (beats per minute)

Data (Mean \pm SD, ) were compared using ANOVA, or the nonparametric Kruskal-Wallis (KW) tests when assumptions of ANOVA were not met. When appropriate (omnibus p-value <0.05), these analyses were followed by a post-hoc test for multiple comparisons: Tukey-Kramer following ANOVA, and Dunn following KW. Mean values within a row with different superscript letters are statistically different $(\mathrm{P}<0.05)$. 
Table 3. Plasma hepcidin and inflammatory cytokine concentrations in Control, MetS, and DIOS subjects $(n=20$ per group)

\begin{tabular}{|lccc|}
\hline & Control & MetS & DIOS \\
& & & \\
Hepcidin-25 $(\mathrm{ng} / \mathrm{mL})$ & $25.4 \pm 16.3^{\mathrm{a}}$ & $35.9 \pm 24.3^{\mathrm{b}}$ & $64.4 \pm 35.5^{\mathrm{c}}$ \\
IL6 (ng/mL) & $1.37 \pm 1.01$ & $1.29 \pm 0.61$ & $1.83 \pm 1.40$ \\
TNF $(\mathrm{ng} / \mathrm{mL})$ & $102 \pm 171$ & $89 \pm 163$ & $133 \pm 184$ \\
MCP-1 $(\mathrm{ng} / \mathrm{mL})$ & $254 \pm 56^{\mathrm{a}}$ & $211 \pm 56^{\mathrm{b}}$ & $267 \pm 75^{\mathrm{a}}$ \\
\hline
\end{tabular}

Data (Mean $\pm \mathrm{SD}$,) were compared using ANOVA, or the nonparametric Kruskal-Wallis (KW) tests when assumptions of ANOVA were not met. When appropriate (omnibus p-value <0.05), these analyses were followed by a post-hoc test for multiple comparisons: Tukey-Kramer following ANOVA, and Dunn following KW. Mean values within a row with different superscript letters are statistically different $(\mathrm{P}<0.05)$. 
Supplementary Figure 1. Phenotype of PBMC performed with FACS

Panel A: Example of final separation of monocytes by CD14 and CD16 sorting. Classical monocytes are represented by the P6 (CD14++CD16-) and P3 (CD14++CD16low), intermediate monocytes by P4 (CD14+ CD16+) population and non-classical monocytes by P5 (CD14-CD16++) population. Panel B: Comparison of Mannose receptor expression in P3 monocytes. Statistical significance is indicated by $*$ for $\mathrm{p}<0.05$ or $* *$ for $<0.01$ 